\title{
Cytological Diagnosis of Salivary Gland Lesions with Histopathological Correlation
}

\author{
Ranbeer Singh ${ }^{1 *}$ and Pravin Sukhadeorao Pawane ${ }^{2}$ \\ 'Dept. of Pathology, Government Medical College, Saharanpur UP, India. \\ ${ }^{2}$ Department of Pathology, Maharaja Agrasen Medical College, Agroha, Haryana, India,
}

\begin{abstract}
Background: The aim of this study was to demonstrate the diagnostic accuracy of FNAC in various salivary gland lesions and it's correlation with histopathology, which helps in the appropriate management of the patient.

Methods: A total of 86 patients were included in this study that was to be investigated for the salivary gland lesions. FNACs were performed using 22 gauge needle. Surgical specimens were received from 68 cases only they were processed and slides were prepared. The cytological and histopathological stained slides were correlated clinically.

Result: Out of total 86 cases 54 were male and 32 were female patients with male to female ratio of 1.7:1. Most common age of presentation was between 21-40 years and maximum patients (42) were in this age group. In this study the most common site of involvement was parotid gland, out of total 86 cases 65 occurred in parotid gland. Mucoepidermoid carcinoma was diagnosed in $3(3.48 \%)$ cases. $2(2.32 \%)$ cases found to have acinic cell carcinoma and both the patients $(100 \%)$ were male. $2(2.32 \%)$ cases found to have Ca. Ex. Pleomorphic adenoma. Metastatic deposit was found in $1(1.16 \%)$ patient.

Conclusion: FNAC of the salivary gland is a safe and reliable technique in the primary diagnosis of salivary gland lesions and has a high diagnostic accuracy, though in case of some tumors due to variable cytomorphology, histological examination is must and proves to be accurate for diagnosis. This study concluded that FNAC of the salivary gland tumors is accurate, simple, rapid and cost-effective for the patient.
\end{abstract}

Keywords: FNAC, Salivary Gland, Salivary Gland Tumors, Diagnostic Accuracy

\section{Introduction}

The technique of Fine Needle Aspiration was initially used to investigate lesions in salivary glands in $1920^{1}$ with improvement and development in 1950 and 1960 and popularization in the seventies ${ }^{1}$. It is a minimally invasive diagnostic modality with minimum cost ${ }^{1}$ used in diagnosis of neoplastic as well as non-neoplastic lesions and being able to differentiate between benign or malignant neoplasia with variable sensitivity and specificity. Salivary gland swellings can result from tumors, an inflammatory process, or cysts.

Salivary gland tumors comprise less than $3 \%$ of all tumors of head and neck. About $80 \%$ are located in the parotids, $10 \%$ in the sub mandibular glands and the remainder being distributed between the sublingual and countless minor salivary glands (Nagarkar N et al 2004) ${ }^{2}$. Major salivary gland tumors tend to be benign whereas minor salivary gland tumors tend to be malignant (Epker $\mathrm{B} \mathrm{N}$ et al 1969) ${ }^{3}$. Proper management of these tumors require an accurate diagnosis by the pathologist, correct interpretation by the surgeon, knowledge of surgical anatomy of salivary glands with a clear understanding of factors leading to recurrence and complications.
A review of the various recent studies shows that the diagnostic sensitivity of FNAC varied from $81-100 \%$, that the specificity varied from $94-100 \%$ and that the diagnostic accuracy varied from $61-80 \%{ }^{4-8}$. Hence, FNAC proves to be simple and accurate method for diagnosis and thus appropriate therapeutic management could be planned earlier. The present study was carried out to find out the prevalence of salivary gland neoplasms, to classify them as per WHO classification, to see associated conditions like sialadenitis, sialolithiasis coexisting with salivary gland neoplasms and to do cyto-histopathological correlation.

\section{Materials and Methods:}

The present study was carried out in the department of Pathology of Government Medical College and Hospital, Saharanpur, Uttar Pradesh. This study included 86 cases of salivary gland lesions that underwent FNAC over a period of 1 year (July 2015-June 2016). The clinical history and relevant clinical examination of all the patients was done. FNACs were performed using 22 gauge needles and $10 \mathrm{ml}$ disposable syringes using Franzen's syringe holder (Gun). The appearance, color, and texture of the aspirate was noted. 
.In each case, one -two wet fixed (Ether/Ethyl alcohol) smears for Papanicolaou stain, 3-4 dry fixed smears for Giemsa stain were prepared, and one-two smears were kept unstained for any further required stain. Only 68 cases were available for histopathology hence cytological and histopathological correlation was done in 68 cases only. We took histopathological diagnosis as gold standard. The diagnostic accuracy of FNAC was established. The detail clinical history and relevant clinical examination of all the patients has been done.

\section{Result}

Out of total 86 cases $54(62.79 \%)$ were male and 32 (37.21\%) were female patients with male to female ratio of $1.7: 1$. Most common age of presentation was between 21-40 years and maximum patients (42) (48.83\%) were in this age group as shown in table no. 2. Out of total 42 cases in this age group 27 male and 15 were female patients. However lesions are present in any age group. The duration of lesions varied from few months to many years. Clinically the benign tumors presented as a painless swelling since many years while malignant tumors presented with persistent pain, fixity and rapid increase in size in a short duration.

In this study the most common site of involvement was parotid gland, out of total 86 cases $65(75.38 \%)$ occurred in parotid gland and $12(13.95 \%)$ occurred in submandibular gland. Nine lesions were found in minor salivary glands of which 5 were in the palate, 3 in the floor of mouth and 1 in the lip as shown in the table 1. The most common gland involved is parotid gland.
On FNA out of total 86 cases, $62(72.09 \%)$ were pleomrphic adenomas, and out of this $38(61.29 \%)$ patients were male while 24 (38.71\%) patients were females, 07 (8.14\%) were of chronic sialadenitis, out of this $05(71.42 \%)$ were male and $02(28.58 \%)$ were female patients. Total $03(3.48 \%)$ were of sialadenosis out of which $01(33.33 \%$ ) was male, $02(66.67 \%)$ were female patients. Benign parotid tumor was found in $1(100 \%)$ female patient that is $(1.16 \%)$ of total 86 patients. Warthin's tumor (Fig.1) was given in 2 $(100 \%)$ male patients i.e. $(2.32 \%)$ of total 86 patients, 3 cases were found to have cystic lesions out of which 2 $(66.67 \%)$ were male and $1(33.33 \%)$ was a female patient shown in table no. 2. Mucoepidermoid carcinoma (Fig. $2,3)$ was diagnosed in $3(3.48 \%)$ cases out of which 2 $(66.67 \%)$ were male and $1(33.33 \%)$ was a female patient. $2(2.32 \%)$ cases found to have Acinic cell carcinoma (Fig. 4 ) and both the patients (100\%) were male. $2(2.32 \%)$ cases found to have $\mathrm{Ca}$. Ex. Pleomorphic adenoma, out of which $1(50.00 \%)$ was male and $1(50 \%)$ was female patient. Metastatic deposit was found in $1(1.16 \%)$ patient and that was a $(100 \%)$ male patient.

On histological examination, out of total 86 cases histology was available in 68 cases. Out of 62 cases of Pleomorphic adenoma histology was available in 52 cases; in 10 cases we did not get histology. On histology the observations were as seen in table no. 3 .

Cytohistological correlation done. Out of total 86 cases diagnosed on cytology $55(63.95 \%)$ were well correlated histologically while $13(15.11 \%)$ cases not correlated and no histology available in $18(20.93 \%)$ cases as seen in table no. 4 .

Table No.1: Shows site wise distribution of salivary gland lesions.

\begin{tabular}{|c|c|c|c|}
\hline Sr. No. & Glands Involved & No. of Cases & Case Percentage \\
\hline 1. & Parotid gland & 65 & $75.38 \%$ \\
\hline 2. & Submandibular gland & 12 & $13.95 \%$ \\
\hline 3. & Palate & 05 & $5.81 \%$ \\
\hline 4. & Lip & 01 & $1.16 \%$ \\
\hline 5. & Floor of Mouth & 03 & $3.48 \%$ \\
\hline & Total Cases & 86 & $100 \%$ \\
\hline
\end{tabular}

Table No.2: Cytological Diagnosis.

\begin{tabular}{|c|c|c|c|c|c|}
\hline Sr.No. & FNA Diagnosis & Males & Females & Total Cases & $72.09 \%$ \\
\hline 1. & Pleomorphic adenoma & $38(61.29 \%)$ & $24(38.71 \%)$ & 62 & 07 \\
\hline 2. & Chronic Sialadenitis & $05(71.42 \%)$ & $02(28.58)$ & 03 & $3.48 \%$ \\
\hline 3. & Sialadenosis & $01(33.33 \%)$ & $02(66.67 \%)$ & 01 & $1.16 \%$ \\
\hline 4. & Benign Parotid tumor & $00(00.00 \%)$ & $01(100 \%)$ & 02 & $2.32 \%$ \\
\hline 5. & Warthin's tumor & $02(100 \%)$ & $00(00.00 \%)$ & 03 & $3.48 \%$ \\
\hline 6. & Cystic Lesions & $02(66.67 \%)$ & $01(33.33 \%)$ & 03 & 03 \\
\hline
\end{tabular}




\begin{tabular}{|c|c|c|c|c|c|}
\hline Sr.No. & FNA Diagnosis & Males & Females & Total Cases & Percentage \\
\hline 7. & Mucoepidermoid Carcinoma & $02(66.67 \%)$ & $01(33.33 \%)$ & 03 & $3.48 \%$ \\
\hline 8. & Acinic Cell Carcinoma & $02(100 \%)$ & $00(00.00 \%)$ & 02 & $2.32 \%$ \\
\hline 9. & $\begin{array}{c}\text { Ca Ex Pleomorphic } \\
\text { adenoma }\end{array}$ & $01(50.00 \%)$ & $01(50.00 \%)$ & 02 & $2.32 \%$ \\
\hline 10. & Metastatic Deposits & $01(100 \%)$ & $00(00.00 \%)$ & 01 & $1.16 \%$ \\
\hline & Total & $54(62.79 \%)$ & $32(37.21 \%)$ & & $100 \%$ \\
\hline
\end{tabular}

Table No. 3: Shows FNA diagnosis and their variations on histopathology

\begin{tabular}{|c|c|c|c|c|c|}
\hline Sr.No & \multicolumn{2}{|l|}{ FNA Diagnosis } & \multicolumn{2}{|l|}{ Histopathology } & \multirow[b]{2}{*}{ Histopathology not available } \\
\hline & Diagnosis & No.of cases & Diagnosis & Cases & \\
\hline \multirow[t]{8}{*}{1.} & \multirow{8}{*}{ Pleomorphic Adenoma } & \multirow{8}{*}{62} & Pleomorphic Adenoma & 41 & \multirow{8}{*}{10} \\
\hline & & & Basal cell adenoma & 02 & \\
\hline & & & Warthin's tumor & 02 & \\
\hline & & & Myoepithelioma, & 01 & \\
\hline & & & Benign lymphoepithelial cyst, & 01 & \\
\hline & & & Mucocele & 02 & \\
\hline & & & Sialadenosis & 02 & \\
\hline & & & Mucoepidermoid carcinoma. & 01 & \\
\hline 2. & Benign parotid tumor & 01 & Pleomorphic adenoma & 01 & - \\
\hline 3. & Warthin's tumor & 02 & Warthin's tumor & 01 & 01 \\
\hline 4. & Cystic lesions & 03 & Mucocele & 02 & 01 \\
\hline \multirow[t]{2}{*}{5.} & \multirow{2}{*}{$\begin{array}{l}\text { Ca. Ex. Pleomorphic } \\
\text { adenoma }\end{array}$} & \multirow{2}{*}{02} & Ca. Ex. Pleomorphic adenoma & 01 & - \\
\hline & & & Mucoepidermoid carcinoma & 01 & - \\
\hline 6. & $\begin{array}{l}\text { Mucoepidermoid } \\
\text { carcinoma }\end{array}$ & 03 & Mucoepidermoid carcinoma & 02 & 01 \\
\hline 7. & Acinic cell carcinoma & 02 & Acinic cell carcinoma & 02 & - \\
\hline 8. & Metastatic deposit & 01 & Metastatic deposit & 01 & - \\
\hline 9. & Chronic sialadinitis & 07 & Chronic sialadinitis & 03 & 04 \\
\hline \multirow[t]{2}{*}{10.} & Sialoadenosis & 03 & Sialoadenosis & 02 & 01 \\
\hline & Total & 86 & & 68 & 18 \\
\hline
\end{tabular}

Table no. 4: shows Cytohistological correlation of salivary gland lesions.

\begin{tabular}{|c|c|c|c|c|c|}
\hline \multirow[b]{2}{*}{ Sr.No. } & \multirow[b]{2}{*}{ Cytology } & \multirow{2}{*}{$\begin{array}{l}\text { No. of } \\
\text { cases }\end{array}$} & \multicolumn{3}{|c|}{ Histology } \\
\hline & & & Histology correlated & $\begin{array}{c}\text { Histology not } \\
\text { correlated }\end{array}$ & $\begin{array}{c}\text { Histology not } \\
\text { available }\end{array}$ \\
\hline 1. & Pleomorphic Adenoma & 62 & $41(66.12 \%)$ & $11(17.74 \%)$ & 10 \\
\hline 2. & Chronic sialadinitis & 07 & $03(42.85 \%)$ & - & 04 \\
\hline 3. & Sialadenosis & 03 & $02(66.67 \%)$ & - & 01 \\
\hline 4. & Benign parotid tumor & 01 & - & $01(100 \%)$ & - \\
\hline 5. & Warthin'tumor & 02 & $01(50 \%)$ & - & 01 \\
\hline 6. & Cystic lesion (Mucocele) & 03 & $02(66.67 \%)$ & 00 & 01 \\
\hline 7. & Mucoepidermoid carcinoma. & 03 & $02(66.67 \%)$ & - & 01 \\
\hline 8. & Ca. Ex. Pleomorphic adenoma & 02 & $01(50 \%)$ & $01(50 \%)$ & - \\
\hline 9. & Acinic cell carcinoma & 02 & $02(100 \%)$ & - & - \\
\hline 10. & Metastatic deposit & 01 & $01(100 \%)$ & - & - \\
\hline Total & & 86 & $55(63.95 \%)$ & $13(15.11 \%)$ & $18(20.93 \%)$ \\
\hline
\end{tabular}




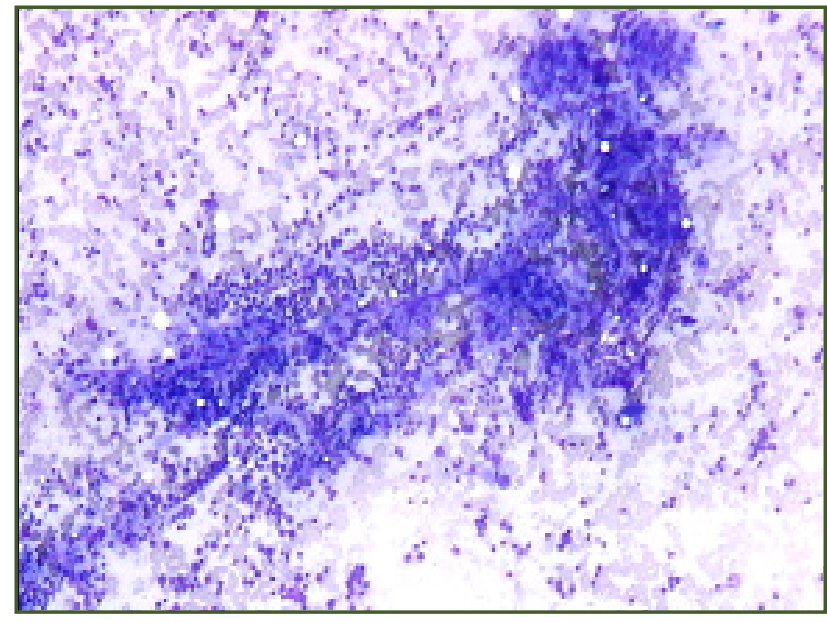

Fig. 1: FNAC, Cytomorphology of Warthin's tumor showing cluster of oxyphilic cells and scattered lymphocytes (Giemsa stain $40 \mathrm{X}$ ).

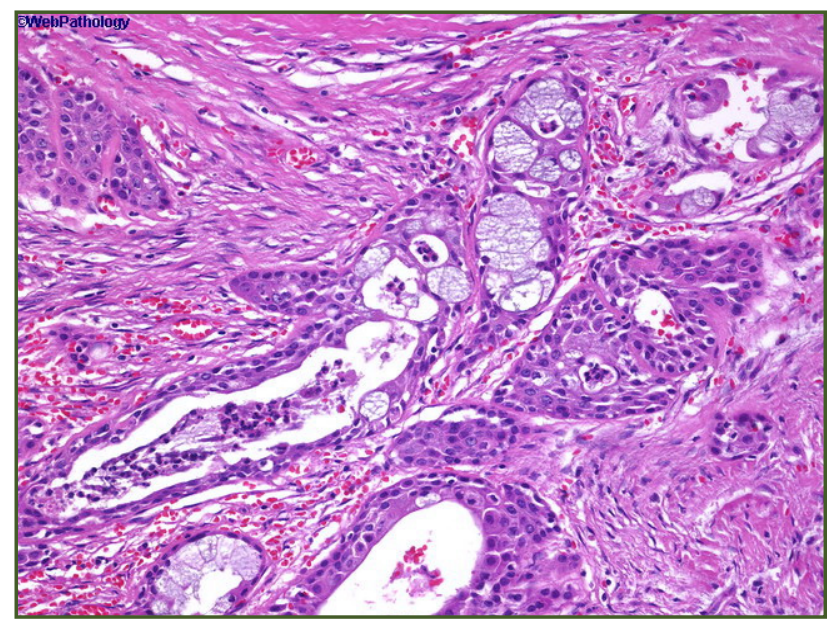

Fig. 3: Histology of Mucoepidermoid Carcinoma showing mucin filled spaces and mucinous cells. (H\&E Stain $40 \mathrm{X}$ ).

\section{Discussion}

In our study most common age of presentation was between 21-40 years and maximum patients $42(48.83 \%)$ were in this age group. Out of total 42 cases in this age group 27 male and 15 were female patients. The duration of lesions varied from few months to many years. Clinically the benign tumors presented as a painless swelling since many years while malignant tumors presented with persistent pain, fixity and rapid increase in size in a short duration.

In this study the most common site of involvement was parotid gland, out of total 86 cases $65(75.38 \%)$ occurred in parotid gland and 12 (13.95\%) occurred in submandibular gland. 9 lesions were found in minor salivary glands of which 5 were in the palate, 3 in the floor of mouth and 1 in the lip. We observed that tumors both benign as well as malignant are more in male than in females this may

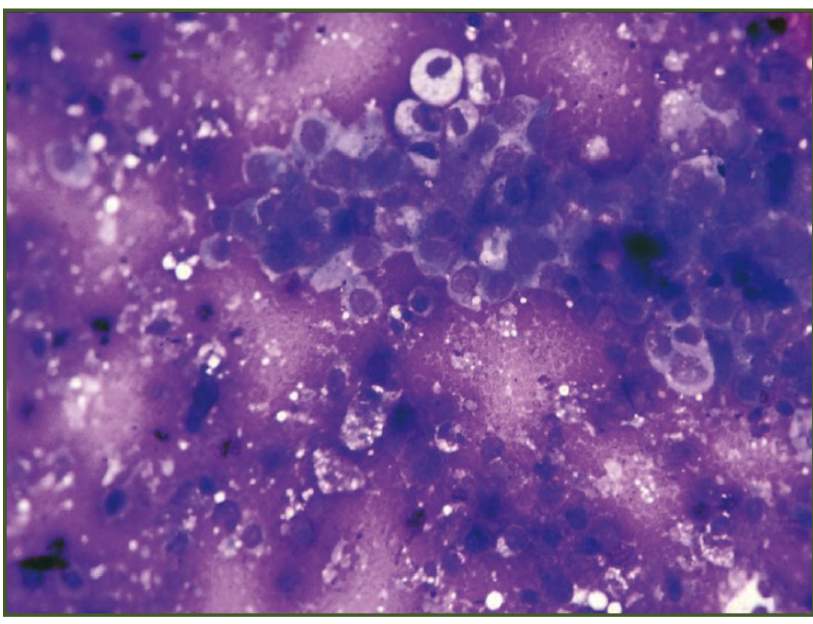

Fig. 2: Cytomorphology of mucoepidermoid Carcinoma showing intermediate cells with abundant vacuolated cytoplasm (Giesma stain $40 \mathrm{X}$ ).

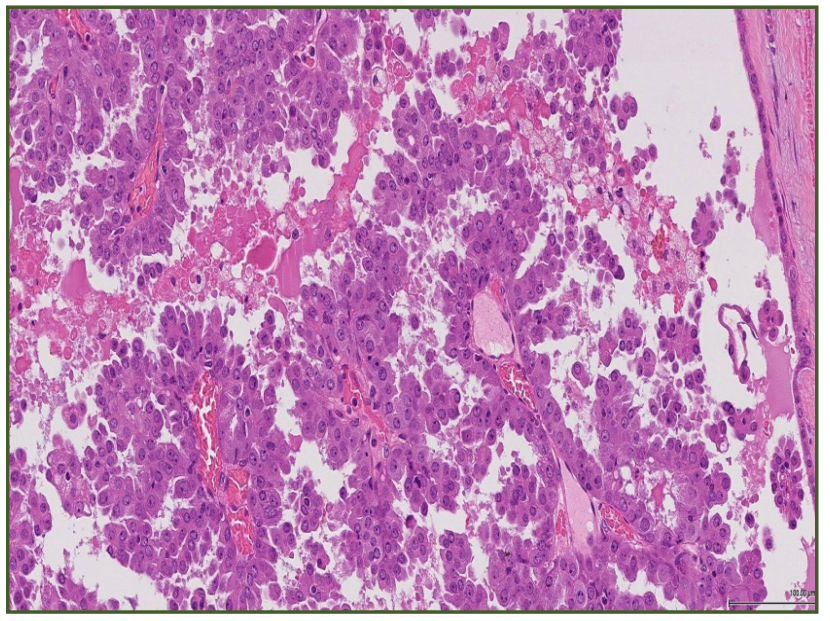

Fig. 4: Histology of Acinic cell Carcinoma showing papillary structures With Acinic cells (H\&E Stain 40 X).

be due to variation in the habits as tobacco, smoking, alcohol consumption as well as exposure to occupational hazards is more in males than females, in this study we found that most of the male patients were smoker and tobacco user. The commonest benign lesion in this study is pleomorphic adenoma and $41(66.12 \%)$ cases of pleomorphic adenomas are correlated cytologically and histologically. The mucoepidermoid carcinoma is the most common malignant lesion reported in this study that is correlated with Nguansangiam et $\mathrm{al}^{9}$. The common nonneoplastic lesion was chronic sialadenitis, common in submandibular gland this is in concordance with study done by Atula $\mathrm{T}$ et $\mathrm{al}^{10}$. Cytomorphologically the diagnosis of mucoepidemoid carcinoma may have resemblance with pleomorphic adenoma, Ca. Ex. Pleomorphic adenoma and 
Warthin's tumor so histological confirmation is required the same is also observed by Layfield L.J.et al ${ }^{11}$.

\section{Conclusion}

Pleomorphic adenoma was the commonest benign tumor while mucoepidermoid carcinoma was the commonest malignant tumor in the present study and the incidence of neoplastic lesions were high in major gland while nonneoplastic lesions were high in minor salivary glands. The overall accuracy in cytohistopathological correlation varied from $63.95 \%$ to more than $80 \%$ depending on the availability of histopathology. FNAC of salivary gland lesions can be more accurate but it has certain limitation in the form of limited availability of histology and limited histological architectural features. However multiple sampling and increasing experience help to minimize the errors $^{12}$. Thus FNAC is safe and cost effective outpatient procedure. F NAC continues to be a reliable diagnostic technique. It is advantageous both for the patients and the clinicians because of its quick results, accuracy, costeffectiveness, and lack of complications to the patient.

\section{Acknowledgements}

Departmental head: Dr. Nausad Husain has given technical support.

\section{Reference}

1. Mahendranath P, Vijay kumar K. Parotid Tumours: ACytohistopathological Correlation of 36 Cases in Khammam.IJSR, volume:4 Issue 7, July 2015.ISSN No. 2277-8178

2. Nagarkar N.M., Bansal S., Dass A. et al--Salivarygland tumors. Indian Journal of otolaryngology and head and neck surgery. 56(1): $31-34,2004$.
3. Epker B.N. and Henry F.A. - Clinical histopathologicand surgical aspects of Intraoral minor salivary glandtumors. Journal of oral surgery. 27: 792-804, 1969.

4. Jayaram G, Dashini M. Evaluation of fine needle aspiration cytology of salivary glands: an analysis of 141 cases. Malays J Pathol. 2001; 23: 93-100.

5. Stow N, Veivers D, Poole A. Fine-needle aspiration cytology in the management of salivary gland lesions: an Australian experience.Ear Nose Throat J. 2004; 83:128-31.

6. Rehman H, Khan MS, Wahid F, Ahmad I. A profile of parotid gland tumours from a tertiary care hospital in Peshawar. JPMI 2011; 25:158-62.

7. Lukas J, Duskova J. Fine needle aspiration biopsy in the diagnosis of tumors and non neoplastic lesions of salivary glands. Bratisl Lek Listy.

8. 2006; 107: 12 - 5 .

9. Piccioni LO, Fabiano B, Gemma M, Sarandria D, Bussi M. Fine needle aspiration cytology in diagnosis of parotid lesions. Acta Otorhinolarygol Ital. 2011; 31:1

10. NguansangiamS. JesdapatarakulS. DhanarakN., and Sosrisakorn K., "Accuracy of fine needle aspiration cytology of salivary lesions: routine diagnostic experience in Bangkok, Thailand,"Asian Pacific Journal of Cancer Prevention,2012; 13(4):1583-1588.

11. AtulaT. GrenmanR., and LaippalaP., "Fine-needle aspiration cytology of submandibular gland lesions,"The Journal of Laryngology \& Otology, 1995; 109 (9):853-858. [7].

12. Layfield L. J. and Glasgow B. J., "Diagnosis of salivary gland tumors by fine-needle aspiration cytology: a review of clinical utility and pitfalls." Diagnostic Cytopathology, 1991; 7(3): 267-272.

13. Jaiswal K N,Johari S P, Shrivastav A C, Shrikhande AV." Study of Salivary Gland Neoplasms. Indian Medical Gazette-March 2015, 96-100.

*Corresponding author:

Dr Ranbeer Singh, H No: 2013, sector 16, 17, Hisar, Haryana 125005. India

Phone: +91 091-01662-9034944345

Email: drpravinpawane@gmail.com

Financial or other Competing Interests: None.

Date of Submission : 12.02.2017

Date of Acceptance : 21.02.2017

Date of Publication : 25.02.2017 